Clinical guidelines

\title{
The investigation of a patient with unexpected venous thrombosis
}

\author{
JT Wilde
}

\section{Summary}

Over recent years a number of hereditary and acquired defects of the circulation's natural anticoagulant mechanisms have been characterised and shown to predispose affected individuals to thrombosis. It is important to attempt to diagnose a thrombophilia state in patients with a thrombotic tendency in order to provide appropriate management, especially during at-risk situations, both for themselves and asymptomatic relatives identified through family studies. This review defines the patients who should be investigated for an underlying thrombophilia state and describes the hereditary and acquired disorders which should be screened for within an investigation profile. The recently identified factor $V$ Leiden mutation which appears to be the most common hereditary cause of a thrombotic tendency is described in detail and descriptions of the more established thrombophilia states are included. Although the factor $V$ Leiden mutation accounts for a significant proportion of cases fulfilling the criteria for thrombophilia screening, a predisposing cause for thrombosis remains unidentifiable in a large number of patients making it likely that over the years to come new thrombophilia states will continue to be identified.

Keywords: thrombosis, thrombophilia, factor $\mathrm{V}$ Leiden mutation

Department of Haematology, University Hospital Birmingham NHS Trust, Edgbaston, Birmingham B15 2TH, UK

JT Wilde
Venous thromboembolic events are commonplace in clinical practice and are associated with significant morbidity and mortality. The frequency of thrombosis increases with age and its occurrence is often precipitated by risk factors such as trauma, surgery, pregnancy, malignancy and prolonged immobilisation. However, in many cases thrombosis can occur spontaneously in the absence of a recognised risk factor and even at a young age.

Blood is normally maintained in a fluid state within the intact circulation by means of complex interactions between the coagulation system, platelets, natural inhibitors of coagulation, the fibrinolytic system and blood vessel endothelial cells. Since the elucidation of the major natural anticoagulant mechanisms over the last 15 years, there has been an increasing recognition that hereditary or acquired defects of these mechanisms can result in a shift of the thrombohaemorrhagic balance in favour of clot formation and predispose individuals to thrombosis. The term 'thrombophilia', initially introduced to describe individuals with hereditary antithrombin III deficiency, ${ }^{1}$ is now applied to all patients with defined familial or acquired disorders of haemostasis regulation which predispose to thrombosis. ${ }^{2}$ There is an increasing awareness amongst clinicians of the importance of investigating patients with a thrombotic predisposition for an underlying thrombophilic state in order to provide appropriate management during future at-risk situations both for themselves and for asymptomatic relatives identified through family studies.

The main aims of this article are to define which patients should be investigated for a thrombophilic state and which investigations should be included within a thrombophilia screen.

\section{Which patients should be investigated?}

The requirement for thrombophilia screening in patients who develop thrombotic events must be assessed on an individual patient basis. However, it is recommended that patients fulfilling any of the criteria summarised in box 1 should be investigated.

\section{Which conditions should be screened for?}

\section{HEREDITARY THROMBOPHILIAS}

Hereditary defects of many of the components of the thrombo-haemorrhagic balance have been identified and implicated as predisposing to clinical thrombosis. In order to verify that a particular defect is associated with a thrombotic tendency it is imperative that the incidence of thrombosis is observed to be higher than normal in similarly affected family members, ie, that the abnormality co-segregates with the clinical manifestations in the pedigree. ${ }^{3}$ Box 2 lists the hereditary disorders that have been proven in this way to be associated with a thrombotic predisposition; investigations for the detection of these conditions must be included in a thrombophilia screening profile.

\section{Factor $V$ Leiden defect}

The factor V Leiden defect is the newest hereditary thrombophilia state to be recognised, having been characterised as recently as $1994 .{ }^{4,5}$ The first clues to its existence came from the work of Dahlbäck et al who, in 1993, as part of the search for unidentified thrombophilia states, reported the phenomenon of activated protein $\mathrm{C}$ resistance in a family with a predisposition to thrombosis. ${ }^{6}$

At sites of thrombus formation activated protein $C$ in association with its cofactor protein $S$ proteolytically neutralises free activated factors $\mathrm{V}$ and VIII damping down the coagulation cascade. In vitro, addition of activated protein $C$ to the activated partial thromboplastin time (APTT) system acts in a similar fashion impairing clot formation which rèsults in a prolongation of the APTT. Addition of activated protein C to the APTT system of Dahlbäck's proband 


\section{Criteria for thrombophilia screening \\ - venous thrombosis or thromboembolism before the age of 45 years \\ - recurrent venous thrombosis or thromboembolism \\ - family history of thromboembolism \\ - thrombosis in an unusual site, eg, hepatic, portal, mesenteric, renal, cerebral or retinal vein \\ - recurrent superficial thrombophlebitis}

Box 1

\begin{tabular}{|l|}
\hline Hereditary disorders \\
predisposing to thrombosis \\
\hline - factor V Leiden defect \\
- protein C deficiency \\
- protein S deficiency \\
- antithrombin III deficiency \\
- dysfibrinogenaemia \\
\hline
\end{tabular}

Box 2 patient resulted in a significant reduction of APTT prolongation, an effect that was reproduced in the other family members with a history of thrombosis. Further studies by Dahlbäck's group and other workers confirmed this observation in other patients with a predisposition to thrombosis and established an autosomal dominant inheritance pattern. ${ }^{6-8}$ The cause of activated protein $C$ resistance was initially presumed to be a deficiency of an unidentified protein $C$ cofactor. ${ }^{6}$ Further work, however, identified a single base pair mutation in the factor $\mathrm{V}$ gene of patients demonstrating activated protein $\mathrm{C}$ resistance resulting in an $\mathrm{Arg}^{506}$ to Gln substitution in the molecule. ${ }^{5,9}$ This position is the primary site for protein-C-mediated lysis and the factor $\mathrm{V}$ Leiden defect has been shown to result in a reduction in the rate of neutralisation by protein $\mathrm{C}$, thus explaining the activated protein $\mathrm{C}$ resistance phenomenon observed in vitro and presumably the associated thrombotic tendency.

The factor $\mathrm{V}$ Leiden defect is screened for in the laboratory using a standardised activated protein C resistance test (Coatest, Quadratech, UK) in which the APTT of test plasma with activated protein $C$ added is expressed as a ratio of the untreated APTT. The normal value is usually $>2.0$ and a ratio below this is deemed activated protein $\mathrm{C}$ resistance, consistent with the presence of the factor V Leiden defect. Bertina et al have in fact shown that the factor V mutation is present in around $90 \%$ of patients demonstrating activated protein $\mathrm{C}$ resistance ${ }^{5}$ and it is now well recognised that 'false' low values can occur in pregnancy and in the presence of antiphospholipid antibodies such as the lupus anticoagulant, elevated factor VIII levels and low protein S levels. As the genetic defect has now been characterised and because of the lack of complete specificity of the activated protein $\mathrm{C}$ resistance test, increasing numbers of laboratories are introducing polymerase chain reaction technology with gene analysis to identify the factor V mutation directly. Furthermore, genetic testing can be performed on patients taking oral anticoagulants who are precluded from activated protein $C$ resistance investigation as the test requires a normal baseline APTT.

Activated protein $\mathrm{C}$ resistance would appear to be the most prevalent cause of thrombophilia, occurring in $6-33 \%$ of consecutive unselected patients with a previous history of thrombosis $3,8,11,12$ and $10-64 \%$ in studies of selected patients. ${ }^{13,14}$ The prevalence of activated protein $\mathrm{C}$ resistance in control patients in these studies was as high as $5-7 \%^{7,8,12}$ and Bertina $e t$ al have validated this observation by finding the factor $\mathrm{V}$ Leiden mutation in $2-4 \%$ of the normal Dutch population. ${ }^{5}$ From their study, Koster et al have estimated that the relative risk ratio for thrombosis in individuals with activated protein $\mathrm{C}$ resistance is of the order of $6.6^{8}$ Homozygotes for the factor V Leiden defect appear to have an increased risk of thrombosis compared to heterozygotes.

\section{Protein $C$ deficiency}

Protein $C$ is a liver-synthesised vitamin-K-dependent glycoprotein which, following interaction with blood vessel endothelial cell surface thrombomodulin at sites of thrombus formation, is converted to its activated form by thrombin and, as mentioned previously, with the aid of its cofactor, protein S, inactivates free factors Va and VIIIa. The association of hereditary protein C deficiency with thrombotic disease was first reported by Griffin et al in $1981^{15}$ and subsequently confirmed in many studies. ${ }^{16,17}$

A spectrum of defects in the protein $\mathrm{C}$ gene have been identified in patients with protein $\mathrm{C}$ deficiency, the majority resulting in a quantitative (type I) deficiency state. ${ }^{18,19}$ Qualitative (type II) defects, characterised by the finding of normal protein $\mathrm{C}$ antigen levels with reduced activity are, however, well recognised. ${ }^{20}$ In haemostasis laboratories protein $\mathrm{C}$ is conventionally measured using a functional assay by either a chromogenic or clotting-based method. If the level is found to be low, an immunological assay is performed in order to identify a type I or type II defect. Levels between $0.55-0.65 \mathrm{U} / \mathrm{ml}$ are consistent with a heterozygous protein $\mathrm{C}$ deficiency state, although it is well recognised that there is a significant overlap between levels in heterozygotes and the lower limit of normality. ${ }^{21}$ Homozygous patients usually have protein $\mathrm{C}$ activity levels of $<0.01 \mathrm{U} / \mathrm{ml}^{22}$

The prevalence of protein $\mathrm{C}$ deficiency varies from $2 \%$ in unselected patients with a history of thrombosis ${ }^{23}$ to $4-8 \%$ in patients selected on the criterion of thrombosis at an early age..$^{24,25}$ As well as a predisposition to limb vein thrombosis and venous thrombosis in unusual locations, protein-C-deficient heterozygotes have an increased tendency to develop superficial thrombophlebitis and are prone to coumarin-induced skin necrosis during the initial phases of anticoagulant therapy. ${ }^{2}$ Homozygotes with very low or undetectable levels of protein $\mathrm{C}$ have a high likelihood of developing life-threatening widespread skin necrosis manifesting as purpura fulminans and often associated with disseminated intravascular coagulation shortly after birth. ${ }^{22}$ 


\section{Protein $S$ deficiency}

Like protein $\mathrm{C}$, protein $\mathrm{S}$ is also vitamin $\mathrm{K}$ dependent and acts as its cofactor in the inactivation of activated factors $\mathrm{V}$ and VIII. About $50 \%$ of circulating protein $S$ is bound to $C 4 b$ binding protein and the rest is in a free form. Only the free form is functionally active. ${ }^{26}$ In the haemostasis laboratory, plasma free protein $S$ levels are measured using immunogenic assays following removal of $\mathrm{C} 4 \mathrm{~b}$ binding protein/protein S complex by polyethylene glycol. Protein S levels are conventionally expressed in terms of 'normal' plasma free protein $S$ rather than total protein S. Protein $S$ deficiency states invariably arise due to a quantitative defect. Although, using functional assays, qualitative protein $S$ deficiencies have been reported ${ }^{27}$ it is now recognised that the factor $V$ Leiden defect can given rise to reduced protein $S$ levels in these assays. All patients previously thought to have a qualitative protein $S$ defect have been shown to have the factor V Leiden mutation and therefore genuine type II defects have yet to be identified. The prevalence of protein $\mathrm{S}$ deficiency in patients with a history of thrombosis is similar to that of protein $\mathrm{C}$, ranging from around $2 \%$ in unselected patients ${ }^{23}$ to $5-8 \%$ of young patients with thrombosis. ${ }^{24,28}$ The clinical manifestations of protein $\mathrm{S}$ deficiency are similar to those of protein $\mathrm{C}$ deficiency.

\section{Antithrombin III deficiency}

Antithrombin III combines with and neutralises thrombin and activated factors IX, $\mathrm{X}$ and $\mathrm{XI}$ within the circulation and is the most important of the natural anticoagulant proteins. Conventionally antithrombin III is measured using functional assays and, as with protein C, if levels are reduced, antithrombin III antigen is determined immunologically to separate type I from thrombin binding site type II defects. Both quantitative and qualitative antithrombin III deficiency states are associated with familial thrombosis. ${ }^{3}$ The prevalence of antithrombin III deficiency is less than that of protein $\mathrm{C}$ and $\mathrm{S}$ deficiencies in both unselected and selected patients with a history of thrombosis $(<1 \%$ and $3 \%$, respectively). ${ }^{23,24}$ However, antithrombin III deficient heterozygotes have a greater risk of developing thrombosis than protein $\mathrm{C}$ deficient heterozygotes with $85 \%$

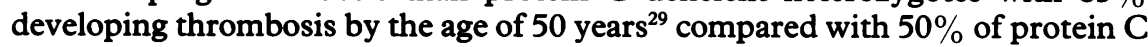
deficient individuals. ${ }^{21}$

\section{Dysfibrinogenaemia}

Although certain forms of dysfibrinogenaemia are well proven to be associated with familial thrombophilia, both venous and arterial, these are very rare. ${ }^{3} \mathrm{~A}$ prolonged thrombin time or reduced fibrinogen levels in an activity-based assay as part of baseline screening tests may indicate the presence of dysfibrinogenaemia and prompt further investigation.

HEREDITARY DEFICIENCY STATES OF OTHER COAGULATION VARIABLES Deficiencies of other coagulation variables that have been implicated as confering a thrombotic risk but for which the case is not fully proven include the following:

\section{Factor XII deficiency}

Activated factor XII plays a role in the fibrinolytic response as one of the activators of plasminogen. An impaired fibrinolytic response may therefore explain the increased thrombotic risk in factor XII deficient patients observed in several studies. Evidence, however, that factor XII deficiency is a cause of familial thrombophilia is weak. ${ }^{3}$ Factor XII deficiency causes a prolongation of the APTT in initial screening tests and will be detected upon further investigation.

\section{Plasminogen}

Although patients with plasminogen deficiency have been reported as having a predisposition to thrombosis, this would appear to be a very uncommon cause of thrombosis. Furthermore, family studies do not entirely support plasminogen deficiency as a risk factor in thrombosis ${ }^{3}$ and therefore plasminogen estimation is not considered a mandatory part of thrombophilia screening.

Tissue plasminogen activator (tPA)/tPA inhibitor ( $P A I)$

An impaired fibrinolytic response to venous occlusion has been reported in $15 \%$ of consecutive patients with a history of venous thrombosis ${ }^{23}$ and in as many as $30 \%$ of selected patients with a history of recurrent thrombosis. ${ }^{30}$ The cause of the impaired fibrinolytic response is principally due to excessive PAI activity, ${ }^{23,30}$ although subnormal tPA release has also been observed. ${ }^{30}$ In many patients, impaired fibrinolysis is not a consistent finding and the relevance of an exaggerated PAI response and reduced tPA release to the pathogenesis of thromboembolic disease is unclear. Furthermore there is no evidence that 
impaired fibrinolysis is associated with a familial thrombotic tendency. For these reasons many laboratories have withdrawn extensive fibrinolytic screening tests from their repertoire of thrombophilia investigations.

\section{Acquired thrombophilia}

Many disorders including malignancy, myeloproliferative states, and the nephrotic syndrome are associated with an increased risk of thrombosis. However, over recent years it has become evident that the commonest cause of an acquired thrombotic tendency is the lupus anticoagulant and it is mandatory that thrombophilia investigations include screening tests for its presence.

\section{THE LUPUS ANTICOAGULANT}

The lupus anticoagulant is a member of a heterogeneous group of autoantibodies termed the antiphospholipid antibodies which are directed against negatively charged phospholipids with differing specificities. It is so called because it interferes with in vitro phospholipid-dependent coagulation tests especially causing prolongation of the APTT. Paradoxically the lupus anticoagulant is associated clinically with both venous and arterial thromboembolism and also with recurrent miscarriage and auto-immune thrombocytopenia..$^{31,32}$ In one large study of patients with the lupus anticoagulant, $25 \%$ developed a thrombotic event, $70 \%$ of which were venous. ${ }^{33}$ Although first described in systemic lupus erythematosus, about half the cases are found in association with other conditions such as other immune disorders, viral infection, lymphoproliferative states and also as a side effect of drug therapy. In some cases the clinical and laboratory manifestations of the lupus anticoagulant are present with no detectable underlying disease. This clinical condition is termed the primary antiphospholipid syndrome.

The pathogenesis of thrombosis and the other clinical effects of the lupus anticoagulant have not been fully elucidated and a discussion of the proposed mechanisms is beyond the scope of this article.

In the haemostasis laboratory, as mentioned above, prolongation of the APTT may indicate the presence of the lupus anticoagulant but as this is a non-specific finding more specialised tests are used to screen for it as part of thrombophilia investigation. The most commonly used test is the dilute Russell viper venom time. The presence of lupus anticoagulant is characterised by the finding of a prolonged dilute Russell viper venom time which does not correct towards normal upon mixing patient with normal plasma but does correct following the addition of disrupted platelets (platelet neutralisation procedure) as the lupus anticoagulant is mopped up by the excess phospholipid. ${ }^{32}$

The prevalence of the lupus anticoagulant in unselected patients with thrombosis is of the order of $2 \%^{23}$ and therefore it is an uncommon cause of thrombosis in general. Although there would appear to be a strong association between the lupus anticoagulant and thrombosis, a direct causal link has yet to be demonstrated. It is possible that the lupus anticoagulant may be a surrogate marker of the presence of another autoantibody which is directly involved in the pathogenesis of thrombosis. More recently interest has been focused upon antibodies against $\boldsymbol{\beta}_{2}$-glycoprotein-1, a naturally occurring heparin-binding glycoprotein. In one study $28 \%$ of patients referred for investigation of thrombophilia were found to have antibodies against $\beta_{2}$-glycoprotein-1. ${ }^{34}$

\section{When should patients be investigated?}

Ideally, thrombophilia screening investigations should be performed following resolution of an acute thrombotic episode and at least one month after anticoagulation has been discontinued. During the initial period of management, heparin therapy reduces plasma antithrombin-III levels and subsequent oral anticoagulation will reduce both protein $\mathrm{C}$ and $\mathrm{S}$ levels. It is not possible to perform the activated protein $\mathrm{C}$ resistance test or lupus anticoagulant screening in patients on oral anticoagulants due to the therapeutic reduction in the vitamin-K-dependent clotting factors. Investigation should be avoided in pregnancy and during the puerperium as protein $\mathrm{C}$ levels may become elevated and protein $S$ levels reduced. The oral contraceptive is associated with a reduction in protein $S$ and antithrombin-III levels and therefore should be discontinued prior to investigation. ${ }^{2}$

Screening test abnormalities must be confirmed upon repeat testing before a definite diagnosis is made. If a hereditary defect is detected arrangements should be made to test immediate family members in order to identify affected individuals and counsel them accordingly. In my centre a thrombophilia status card is issued to individuals following diagnosis.

full blood count

prothrombin time, APTT, thrombin time, fibrinogen

- activated protein $C$ resistance test

- protein Cactivity assay

- free protein $S$ antigen assay

- antithrombin-III activity assay

- lupus anticoagulant screen 


Summary points
- hereditary and acquired defects of
natural anticoagulant mechanisms
are now well recognised as
predisposing to thrombosis
- it is important to identify affected
individuals in order to provide
appropriate management especially
during at risk situations
patients presenting with
thrombosis before the age of 45
years, with recurrent thrombosis,
with a family history of thrombosis
or with thrombosis in an unusual
site should be considered for
screening for a thrombophilia state
it is essential that thrombophilia
investigation profiles include tests
to screen for the major
thrombophilia states namely the
factor $V$ Leiden mutation, protein
C deficiency, protein $S$ deficiency,
antithrombin-III deficiency,
dysfibrinogenaemia and the lupus
anticoagulant

Box 4

Table Prevalence of main thrombophilia states in patients with thrombosis

\begin{tabular}{lll}
\hline & Unselected patients $(\%)$ & Selected patients $(\%)$ \\
\hline Factor V Leiden defect & $6-33$ & $10-64$ \\
Protein C deficiency & 2 & $4-8$ \\
Protein S deficiency & 2 & $5-8$ \\
Antithrombin-III deficiency & $<1$ & 3 \\
Lupus anticoagulant & 2 & - \\
\hline
\end{tabular}

\section{Concluding remarks}

Although thromboembolic disease is common, a predisposing thrombophilia state is identifiable in less than $50 \%$ of patients. The recent discovery of the factor V Leiden mutation would appear to account for a large proportion of cases of hereditary thrombophilia but there remains a substantial number of individuals with a strong family history of thrombosis in whom a definite diagnosis cannot be made. It is likely, therefore, that there are hereditary thrombophilia states still to be identified and it is possible that more will be characterised over the coming years, leading to a broadening of the thrombophilia screening repertoire. Although individuals with a thrombophilia defect are at life-long risk of thrombosis it is not inevitable that they will develop thrombosis during life. Spontaneous thrombotic episodes are in fact rare and are usually only triggered by exposure to an acquired thrombophilic insult. ${ }^{35}$ As affected individuals are at a significantly higher risk of developing thrombosis when exposed to a prothrombotic stimulus, it is important that they are identified so that appropriate management can be undertaken to minimise the thrombotic risk in such situations.

13 Legnani C, Palareti G, Biagi R, Coccheri S. Activated protein $C$ resistance in deep vein thrombosis. Lancet 1994; 343: 541-2.

14 Griffin JH, Evatt B, Wideman C, Fernandez JA. Anticoagulant protein $C$ pathway defective in majority of thrombophilia patients. Blood 1993; 82: 1989-93.

15 Griffin JH, Evatt B, Zimmerman TS, Kleiss AJ, Wideman C. Deficiency of protein $C$ in congenital thrombotic disease. $f$ Clin Invest congenital thrombotic

16 Bertina RM, Broekman AW, van der Linden IK, Mertens $\mathrm{K}$. Protein C deficiency in a IK, Mertens $\mathbf{K}$. Protein C deficiency in a
dutch family with thrombotic disease. Thromb dutch family with throm

17 Horellon MH, Conard J, Bertina RM, Samama $M$. Congenital protein $C$ deficiency and thrombotic disease in nine french families. $B M F$ 1984; 289: 1285-7

18 Romeo G, Hassan HJ, Staempfli S, et al. Hereditary thrombophilia: identification of nonsense and missense mutations in the pro-
tein $C$ gene. Proc Natl Acad Sci USA 1987; 84: 2829-32.

19 Reitsma PH, Poort SR, Allaart CF, Briët E, Bertina RM. The spectrum of genetic defects in a panel of 40 dutch families with symin a panel of 40 dutch families with symptomatic protein C deficiency type 1: hetero890-4.

20 Bertina RM, Broekmans AW, Krommenhoek van Es $C$, van Wijngaarden $A$. The use of a functional and immunologic assay for plasma protein $C$ in the study of the heterogeneity of congenital protein $\mathrm{C}$ deficiency. Thromb Haemost 1984; 51: $1-5$.

21 Allaart CF, Poort SR, Rosendaal FR, Reitsma PH, Bertina RM, Briët E. Increased risk of venous thrombosis in carriers of hereditary protein C deficiency defect. Lancet 1993; 341: 134-8.

22 Marler RA, Montgomery RR, Broekmans AW. Report on the diagnosis and treatment of homozygous protein C deficiency: report of homozygous protein C deficiency: report of the Working party on Homozygous Protein C
deficiency of the ICTH Subcommittee on deficiency of the ICTH Subcommittee on Protein C and Prote

23 Malm J, Laurell M, Nilsson IM, Dahlbäck B. Thromboembolic disease - critical evaluation of laboratory investigation. Thromb Haemost 1992; 68: 7-13.
24 Gladson CL, Scharrer I, Hach V, Beck KH, Griffin JH. The frequency of type I heterozygous protein $S$ and protein $C$ deficiency in 141 unrelated young patients with venous thrombosis. Thromb Haemost 1988; 59: 18-22.

25 Broekmans AW, van der Linden IK, JansenKoster Y, Bertina RM. Prevalence of protein $C$ (PC) and protein $S$ (PS) deficiency in patients with thrombotic disease. Thromb Res 1986; suppl VI: 135.

26 Dahlbäck B. Inhibition of protein Ca cofactor function of human and bovine protein $S$ by C4b-binding protein. I Biol Chem 1986; 261: 12022-7.

27 Mannucci PM, Valsecchi C, Krachmalnicoff A, Faioni EM, Tripodi A. Familial dysfunction of protein S. Thromb Haemost 1989; 62: 763-6.

28 Engasser L, Broekmans AW, Briët EE, Emile JP, Brommer MD, Bertina RM. Hereditary
protein $S$ deficiency: clinical manifestations. Ann Intern Med 1987; 106: 677-82.

29 Thaler E, Lechner K. Antithrombin III deficiency and thromboembolism. Clin Haematol 1981; 10: 369-90.

30 Juhan-Vague I, Valadier J, Alessi MC, et al. Deficient t-PA release and elevated PA inhibitor levels in patients with spontaneous or hibitor levels in patients with spontaneous or recurrent deep venous th
Haemost 1987; 57: 67-72.

31 Creagh MD, Greaves M. Lupus anticoagulant. Blood Rev 1991; 5: 162-7.

32 Triplett DA. Lupus anticoagulants and thrombosis. In: Poller L, Thomson JM, eds. Thrombosis and its management. Edinburgh: Churchill Livingstone, 1993; pp 98-112.

33 Gastineau DA, Kazmier FL, Nichols WL, Bowie EJW. Lupus anticoagulant: an analysis of the clinical and laboratory features of 219 cases. Am $\mathcal{H}$ Haematol 1985; 19: 265-75.

34 Cohen H, McNally T, Dave M, Mackie IJ, a marker for thrombosis. Br $\mathcal{F}$ Haematol 1995; 89 (suppl 1): 7 .

35 Schafer AI. Hypercoagulable states: molecular genetics to clinical practice. Lancet 1994; 344: 